\title{
Russian Speaking Jewish Identity Study
}

\section{Alexey Gotsdanker*}

Department of Psychology, Walden University, Israel

\begin{abstract}
Members of small ethnics groups seem to combine a culture of the country they live and their national, race identity. In this study, we am going to distinguish unique elements that belong to particular ethnic groups core self-concept factors. This study utilizes a standard questionnaire measure of ethnic identity. The internet-based questionnaire was administered to 380 participants from Russian-speaking countries. Participants were invited via different internet sites; from 23 to 72 (Mean 43) years old, 56\% males, $44 \%$ females. Reliability, assessed by Cronbach's alpha, was 0.91 and 0.92 for the ethnic identity scales and 0.91 for the ethnic self-concept scale. The relationship of ethnic identity to various factors and self-esteem was examined.
\end{abstract}

Keywords: Jew; Identity; Immigration

\section{Russian Speaking Jewish Identity Study}

National-wide culture, values, legends and heroes tend to be not homogenous. Small ethnic groups struggle to keep their one culture, values, religion, and self-concept and fit a culture of the country they live. In nowadays it is not possible to maintain high level of isolation of one of the group, and it makes impossible to prevent dispersion of values between small and big groups. In $1990^{\text {th }}$ a million of Jewish people repatriated to Israel from ex-Soviet countries. Now it is impossible to measure what was the identity of ex-Soviet repatriates, but it is possible to measure self-concept and values of Jews living in ex-Soviet countries and in Israel today. This study presents data from first part of the research - Jews living in Russian speaking countries. The second part and the final conclusion will be submitted later when data from Russian-speaking Israeli Jews will be collected.

The purpose of the study is to find factors that correlate with ethnical self-identity and check the assumption that self-identity of members of small ethical groups will be overmixed with nation-level identity. So, together with factors we check following hypothesis:

$\mathrm{H} 1$ : It is no significant correlation between self-identity of a small ethnical group and big national group.

\section{Design of the Study and Method}

The study is based on the standard ethnic identity scale for the purpose to be able to analyses data in comparable form with other studies [1]. These 57 items with 6-grade Likert scale was translated into Russian language. To measure small group identity, we developed two scales based on Social Identity Theory [2-4]. It is two blocks of four items with 5-grade Likert scale:

B1. The fact that I am Russian, is an important part of my identity.

B2. When I'm talking about Russians, I say "we" instead of "them".

B3. When someone criticizes Russians, I take it personally.

B4. For me it is important to consider myself a Russian.

C1. The fact that I am a Jew, is an important part of my identity.

C2. When I'm talking about Jews, I say "we" instead of "them".

C3. When someone criticizes the Jews, I take it personally.

C4. For me it is important to consider myself as Jew.
The study also collects some demographic data, age, gender, citizenship, occupation and so on.

The study was administrated as a web-based questionnaire on the Survey Monkey platform. Unique link invitation to the study was randomly sent to prospect participants from my contact list. Also small articles - invitations to the survey were published on the Facebook and popular Russian-speaking internet magazine Snob. The sample as a whole was relatively mature $(M=42.41, S D=10.59)$, nearly half (56\%) were male.

\section{Result}

Cronbach's alphas for the self-identity scale were 0.92 for Jews and 0.91 for Russian, respectively. There was a nonsignificant correlation of $0.10(\mathrm{p}=\mathrm{n} . \mathrm{s})$ between Jewish and Russian self-identity cumulative scales (C5 and B5).

\section{Factor Analysis}

Initially, the factorability of the 57 identity items was examined. Several well-recognized criteria for the factorability of a correlation were used. Firstly, 53 of the 57 items correlated at least 0.3 with at least one other item, suggesting reasonable factorability. Secondly, the Kaiser-Meyer-Olkin measure of sampling adequacy was 0.73 , above the recommended value of 0.6 , and Bartlett's test of sphericity was significant $\left(\chi^{2}(378)=4418.29, p<0.001\right)$. The initial Eigen values showed that the first factor explained $21 \%$ of the variance, the second factor $13 \%$ of the variance, and a third factor $7 \%$ of the variance. The three factor solution, which explained $41 \%$ of the variance. The scree plot demonstrates after three factors the insufficient number of primary loadings (Figure 1 and Table 1).

Based on these findings we created new cumulative dimensions: Agreeableness - based on the Factor 1, Authoritarianism - based on the Factor 2, and Comfort - based on the Factor 3 items. These variables were significantly correlated: Agreeableness with Jewishidentity $r(124)=0.26, p<0.01$, Authoritarianism with Jewish-identity

*Corresponding author: Aryeh Gotsdanker, Department of Psychology, Walden University, Israel, Tel: +972546598989; E-mail: gotsdanker@gmail.com

Received July 04, 2018; Accepted July 17, 2018; Published July 25, 2018

Citation: Gotsdanker A (2018) Russian Speaking Jewish Identity Study. Arts Social Sci J 9: 389. doi: 10.4172/2151-6200.1000389

Copyright: ( 2018 Gotsdanker A. This is an open-access article distributed under the terms of the Creative Commons Attribution License, which permits unrestricted use, distribution, and reproduction in any medium, provided the original author and source are credited. 


\begin{tabular}{|c|c|c|c|}
\hline \multicolumn{4}{|c|}{ Structure Matrix } \\
\hline & \multicolumn{3}{|c|}{ Factor } \\
\hline & 1 & 2 & 3 \\
\hline 55. It is important that all of his friends and relatives can rely on him & 0.734 & 0.136 & 0.020 \\
\hline 47. It is important to pay attention to all the needs of the people close to him & 0.673 & 0.080 & 0.057 \\
\hline 34. It is important to listen to and understand people different from him & 0.669 & -0.077 & 0.137 \\
\hline 5. It is important to protect the weak and vulnerable people in society & 0.664 & -0.125 & 0.200 \\
\hline 27. It is important to be reliable and trustworthy friend & 0.663 & 0.013 & 0.180 \\
\hline 45. It is important to protect the environment from destruction or pollution & 0.658 & 0.070 & 0.110 \\
\hline 52. It is important that all people are treated fairly, even if he himself does not know them & 0.658 & -0.031 & 0.255 \\
\hline 38. It is important to be humble & 0.654 & 0.001 & -0.038 \\
\hline 8. It is important to protect nature & 0.646 & -0.115 & 0.120 \\
\hline 25. It is important to help the people dear to him & 0.640 & -0.026 & 0.019 \\
\hline 39. It is important to expand your horizons & 0.627 & -0.199 & 0.270 \\
\hline 42. It is important to comply with all laws & 0.621 & 0.265 & -0.029 \\
\hline 11. It is important to take care of the people close to him & 0.615 & 0.001 & -0.021 \\
\hline 31. It is important to follow the rules, even when no one is watching & 0.602 & 0.254 & -0.140 \\
\hline 19. It is important that the people he knows are fully confident in him & 0.601 & 0.207 & -0.084 \\
\hline 15. It is important not to break the rules or regulations & 0.586 & 0.234 & -0.152 \\
\hline 40. It is important to honor the customs and traditions of his culture & 0.581 & 0.307 & -0.189 \\
\hline 14. It is important to be tolerant of a variety of individuals and groups & 0.574 & -0.171 & 0.170 \\
\hline 7. It is important never to brag and behave arrogantly & 0.570 & -0.042 & -0.127 \\
\hline 37. It is important that everyone in the world had the same opportunities in life & 0.563 & -0.191 & 0.174 \\
\hline 57. It is important to accept people as they are, even when he does not agree with them & 0.556 & -0.251 & 0.144 \\
\hline 51. It is important never to annoy other people & 0.526 & 0.093 & 0.114 \\
\hline 21. It is important to participate in activities for the protection of nature & 0.516 & 0.233 & 0.131 \\
\hline 22. It is important to never let anyone annoy & 0.513 & 0.076 & -0.040 \\
\hline 18. It is important to maintain traditional values and views of the world & 0.502 & 0.491 & -0.280 \\
\hline 4. It is important not to upset other people & 0.501 & -0.136 & 0.150 \\
\hline 54. It is important never to seek public attention or approval & 0.425 & 0.067 & -0.112 \\
\hline 53. It is important to never put yourself in danger & 0.293 & 0.259 & 0.159 \\
\hline 41. It is important to be the one to tell others what to do & -0.143 & 0.732 & 0.183 \\
\hline 12. It is important to have a power that can give the money & -0.175 & 0.637 & 0.288 \\
\hline 24. It is important to save face in the eyes of others & 0.139 & 0.625 & 0.138 \\
\hline 29. It is important to have the power to force people to do what he wants & -0.301 & 0.610 & 0.245 \\
\hline 44. It is important to have expensive things that show his wealth & -0.339 & 0.589 & 0.067 \\
\hline 32. It is important to be very successful & 0.009 & 0.579 & 0.547 \\
\hline 6. It is important that people do what he tells them & -0.015 & 0.572 & 0.190 \\
\hline 20. It is important to be rich & -0.138 & 0.544 & 0.332 \\
\hline 9. It is important to never be disgraced & 0.374 & 0.528 & 0.131 \\
\hline 49. It is important never to be humiliated & 0.133 & 0.499 & 0.201 \\
\hline 33. It is important to follow a family or religious customs & 0.450 & 0.489 & -0.246 \\
\hline 26. It is important to feel safe and be safe & 0.292 & 0.438 & 0.351 \\
\hline 13. It is important to try to be healthy and take care of your health & 0.275 & 0.360 & 0.080 \\
\hline 2. it is important for stability and order in society & 0.233 & 0.305 & 0.113 \\
\hline 30. It is important to plan their actions regardless of other people & 0.036 & 0.224 & 0.053 \\
\hline 3. It is important to have a good time & 0.024 & 0.352 & 0.619 \\
\hline 36. It is important to enjoy life and have fun & -0.114 & 0.334 & 0.609 \\
\hline 48. It is important that people recognize his achievements & -0.045 & 0.468 & 0.560 \\
\hline 17. It is important to have ambitious goals in life & 0.202 & 0.320 & 0.530 \\
\hline 56. It is important to be free and to choose what to do & 0.048 & 0.055 & 0.515 \\
\hline 43. It is important to diversify your experience & 0.318 & 0.063 & 0.474 \\
\hline 46. It is important to use every opportunity to have fun & -0.210 & 0.381 & 0.444 \\
\hline 10. It is important to always look for diversity in activity & 0.120 & -0.030 & 0.440 \\
\hline 35. It is important that his country had been a strong and able to defend its citizens & 0.358 & 0.185 & 0.390 \\
\hline 50. It is important that his country would defend itself against any threats & 0.255 & 0.187 & 0.348 \\
\hline 28. It is important excitement in life, even if it involves a risk & -0.011 & 0.189 & 0.342 \\
\hline 23. It is important to be original & 0.177 & 0.142 & 0.320 \\
\hline 16. It is important to make decisions concerning his life & 0.035 & 0.015 & 0.237 \\
\hline 1. It is important to understand things in their own way & -0.043 & 0.065 & 0.208 \\
\hline
\end{tabular}

Table 1: The factor loading matrix for this final solution. 


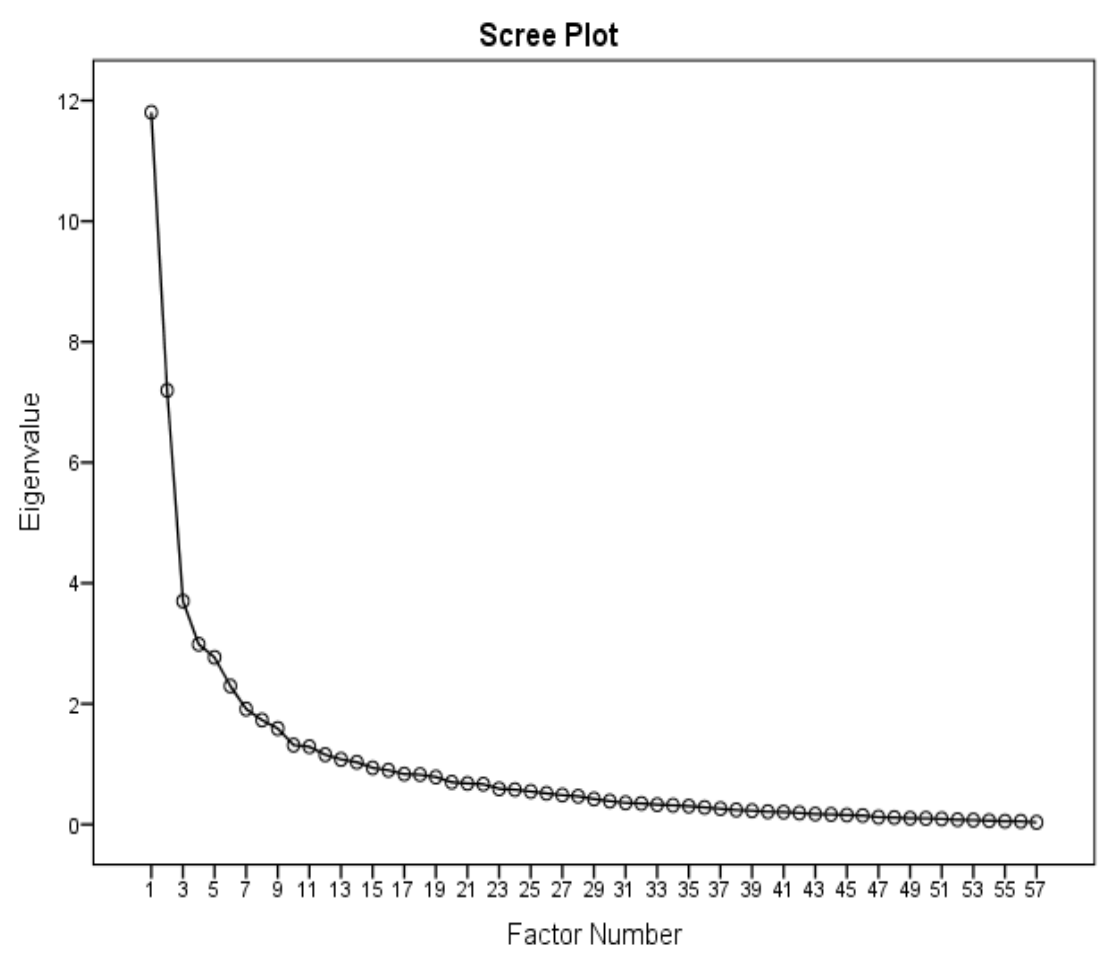

Figure 1: The scree plot demonstrates after three factors the insufficient number of primary loadings.

$r(128)=0.18, p<0.05$, Comfort with Russian-identity $r(130)=-0.19$, $p<0.05$.

\section{References}

1. Phinney JS (1992) The multigroup ethnic identity measure a new scale for use with diverse groups. Journal of adolescent research 7: 156-176.
2. Myers DG (2014) Social psychology.

3. Myers DG, Lamm H (1976) The group polarization phenomenon. Psychological Bulletin 83: 602-627.

4. Tajel H, Billig MG, Bundy RP, Flament C (1971) Social categorization and intergroup behaviour European. Journal of Social Psychology 1: 149-178. 